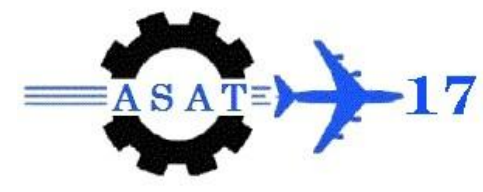

\title{
Influence of Laser Process Parameters on Properties of Alumina Parts Produced By SLS
}

\author{
E. M. Fayed ${ }^{*}$, A.S. Elmesalamy ${ }^{\dagger}$, M. Sobih ${ }^{\ddagger}$ Y. Elshaer ${ }^{\S}$
}

\begin{abstract}
Direct selective laser sintering (SLS) is an additive manufacturing technique for the fabrication of near net shaped parts directly from computer-aided design data by sintering together different layers with the help of a laser source. This paper presents an investigation of the physical properties (density and porosity) of alumina $\left(\mathrm{Al}_{2} \mathrm{O}_{3}\right)$ samples produced by SLS. Some input parameters, namely laser power and scan speed were selected for the investigation. The aim of this work is to understand the effect of these sintering parameters on the quality of the sintered layer (surface roughness), physical properties (density and porosity) and microstructure (grain size) are investigated. The results showed that maximum density of the sintered ceramics layers are of $3.54 \mathrm{gm} / \mathrm{cm} 3$ and minimum porosity of $4.34 \%$ were obtained at laser power $230 \mathrm{~W}$ and laser scanning speed $150 \mathrm{~mm} / \mathrm{min}$. The morphology was analyzed by means of field emission scanning electron microscope. Laser power and Scan speed were found to have a great influence on the surface roughness and morphology.
\end{abstract}

Keywords: Additive manufacturing, selective laser sintering; physical properties; and ceramics.

\section{Introduction}

Additive manufacturing (AM) is the process of joining materials to make objects from 3D model data, usually layer upon layer [1]. This technique enables the manufacturers to build very complex parts without any need of tools or fixtures and with-out producing any waste material. Recently, demands for the direct manufacture of full functional engineering ceramic components in different industry sectors such as motor racing, aerospace, pneumatics, automotive, and functional prototypes have increased greatly. One of the main processes employed in AM is selective laser sintering (SLS). In this process, a part is built up layer by layer through the consolidation of powder particles with a focused laser beam that selectively scans the surface of the powder bed. Consolidation occurs either by actual fusion of the powder particles or by diffusion bonding. Laser sintering has been utilized to build parts from polymeric materials like styrene, nylon, glass-filled nylon, and polycarbonate plastics, metallic and ceramic materials [2]. However, production of ceramic objects by SLS is much more complicated and has been pursued through two different approaches, known as indirect and direct laser sintering.

Egyptian Armed Forces, Egypt; eslamfayed2009@gmail.com

Egyptian Armed Forces, Egypt.

Mechatronics Systems Engineering Department, October University for Modern Sciences and Arts (MSA),

Giza, Egypt.

$\S \quad$ Egyptian Armed Forces, Egypt. 
Indirect laser sintering involves the sintering of ceramic powders either mixed with a binder or coated with a polymer. Hence, powder particles are consolidated by the melting and binding capacity of low melting point polymers, which are eventually burnt off. The part is subsequently infiltrated with a low melting point metal [2]. In direct laser sintering, highdensity objects are created by the sintering of ceramic powders, recently also reactive materials like alumina $\left(\mathrm{Al}_{2} \mathrm{O}_{3}\right)$, without the aid of a binder. Research in recent years has identified the potential of this process to build ceramic components that can act as functional prototypes and manufacturing [2]. In fact, with the proper choice of input conditions, direct laser sintering, generally known as direct ceramic laser sintering can build full dense parts with mechanical properties equivalent or better than those of parts produced by conventional manufacturing. Due to its versatility of materials and shapes, the main advantage of SLS is to produce ceramic complex shaped components in one step, but it also has drawbacks that require careful process control: the high temperature gradients and densification ratio during the process yield high internal stresses or part distortion which may result in bad physical properties and surface roughness [2].

Previous researchers have studied the effect of process parameters (laser power and laser scanning speed) on density, surface roughness, and concluded that laser power is directly proportional to each response. Furthermore, laser scanning speed was found to be inversely proportional with all of these responses [3-7].

The main objective of this work is to understand the effect of significant laser sintering parameters (laser power and laser scanning speed,[8], on the quality of the sintered sample (surface roughness, Ra), physical properties (density and porosity) and microstructure of ceramic laser-sintered samples. The experimental methodology has been described and the results that arise from the experiment have been assessed and discussed. The work results were extended to establish a statistical model which control and optimize the laser sintering parameters according to our published work [9].

\section{Experimental Study}

The laser system used in the experiments was a pulsed Nd: YAG laser (LUMONICS JK 700 laser machine) with maximum laser power of $330 \mathrm{~W}$ and wavelength of $1.064 \mu \mathrm{m}$. The minimum beam diameter is $0.92 \mathrm{~mm}$ at $10 \mathrm{~mm}$ below the gas nozzle tip. The laser beam is moved over the powder surface according to the predefined 2D pattern using a 3-D CNC table. The laser sintering process was carried out at the defocused plane to cover big area in small time and to minimize the formation of plasma [10], which could scatter the powder particles. According to screening set of experiments, the height of the laser nozzle plane adjusted to be at $30 \mathrm{~mm}$ above the powder surface with defocused distance of $20 \mathrm{~mm}$. The defocused spot size diameter at low power is $1.68 \mathrm{~mm}$. Above this plane the alumina laser sintering was not accomplished and below this plane the plasma formation increased.

The ceramic material used was a high purity alumina $\left(\mathrm{Al}_{2} \mathrm{O}_{3}\right)$ with a mean particle size of $8 \mu \mathrm{m}$. Alumina powder was pressed by uniaxial dry pressing at $50 \mathrm{MPa}$ using a mild steel die assembly and uniaxial press (SANTEC 100 ton hydraulic press, India) into square layer of 50 $\mathrm{x} 50 \mathrm{~mm}$. Then the sample is ready for sintering process.

A series of screening experiments or runs were carried out on the compacted alumina powder to determine the window of acceptance in which the sintering is successfully accomplished and to determine the maximum and minimum limits of both control factors (laser power from $150 \mathrm{~W}$ to $300 \mathrm{~W}$ at laser scanning speed from $40 \mathrm{~mm} / \mathrm{min}$ to $180 \mathrm{~mm} / \mathrm{min}$ ). 
The working parameter groups for all laser irradiations are shown in Table 1. The pulse width and repetition rate are constant for all average powers. But the average power changes with change of pulse height (\%) due to its significance. The effect of variation of laser power and laser scanning speed inside the acceptance window on the quality of sintered samples (surface roughness, $\mathrm{Ra}$ ), physical properties (density and porosity) and microstructure were studied.

A thermocouple R-TYPE is calibrated and used for on line temperature measurement and control of the laser process to ensure that these parameters reaches to the sintering temperature of alumina which around $1600^{\circ} \mathrm{C}$. The output of the thermocouple is red by using data acquisition (NATIONAL INSTRUMENT USB-9162) that converts the mille voltage to real temperature by using LAB VIEW software as shown as in Figure 1. Three temperature measurements were performed for each parameter inside the acceptance window.

The surface roughness of the laser sintered monolayer was determined using surface roughness meter (Mitutoyo SJ.201), the average value of ten measurements was considered for each monolayer. The physical properties in terms of bulk density and apparent porosity were determined using liquid displacement technique (Archimedes) by using METTLER TOLEDO weight measurement. The morphology was analyzed by means of field emission scanning electron microscope (SEM).

Table 1. Working Parameter Group for All Powers

\begin{tabular}{|c|c|c|c|c|}
\hline $\begin{array}{c}\text { Power } \\
(\mathrm{W})\end{array}$ & $\begin{array}{c}\text { Pulse height } \\
(\%)\end{array}$ & $\begin{array}{c}\text { Pulse width } \\
(\mathrm{ms})\end{array}$ & $\begin{array}{c}\text { Repetition } \\
\text { rate }(\mathrm{Hz})\end{array}$ & $\begin{array}{c}\text { Pulse } \\
\text { energy (J) }\end{array}$ \\
\hline 150 & 24.5 & 1 & 150 & 1 \\
\hline 170 & 25.5 & 1 & 150 & 1.13 \\
\hline 200 & 28.5 & 1 & 150 & 1.33 \\
\hline 230 & 30 & 1 & 150 & 1.53 \\
\hline 250 & 31.5 & 1 & 150 & 1.66 \\
\hline 270 & 33 & 1 & 150 & 1.81 \\
\hline 300 & 35 & 1 & 150 & 2 \\
\hline
\end{tabular}

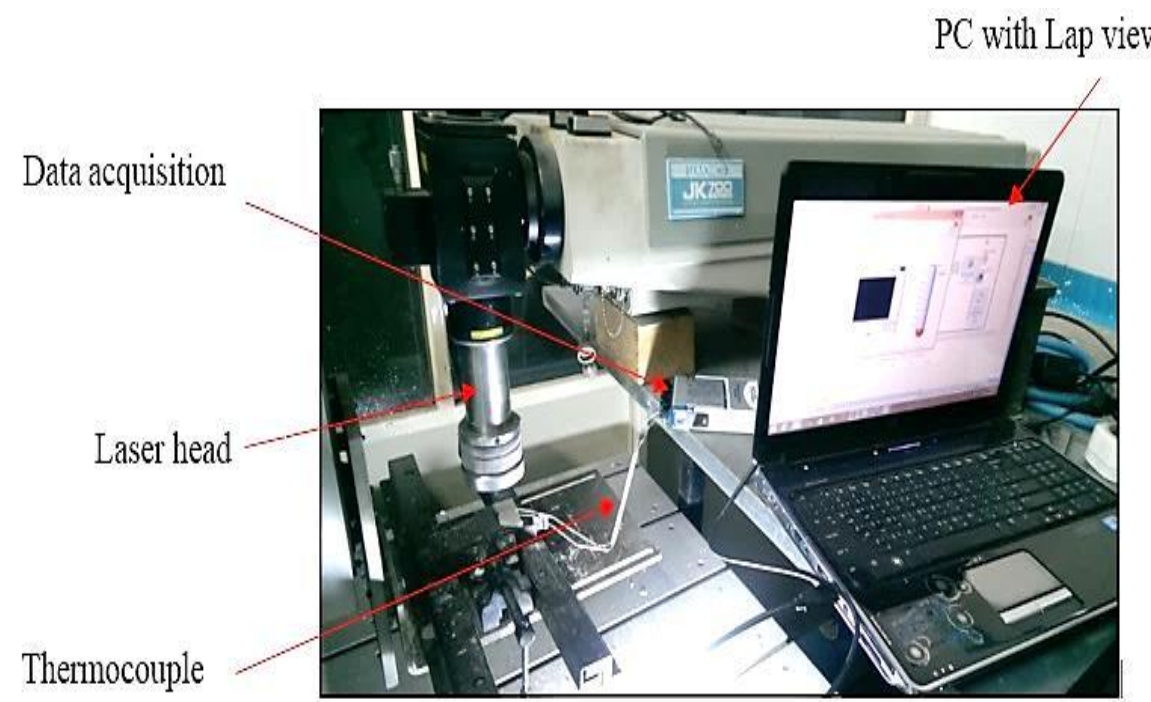

Figure 1: Thermocouple with DAQ system used for temperature measurement 


\section{Results and Discussions}

\subsection{Real time temperature analysis by a thermocouple}

The temperature is a crucial factor in analyzing the laser sintering process. A thermocouple RTYPE connected to a data acquisition system was used to measure the temperature when the Nd:YAG laser beam scanned over an alumina powder surface. The analysis shows that temperature at the surface of alumina powder is inversely proportional to laser scanning speed and directly proportional to laser power due to high beam absorption in case of higher laser power and/or lower scanning speed as shown successively in Figure 2 and Figure 3. The recorded temperatures indicate that solid state sintering is the main sintering mechanism during the laser sintering process. However, by increasing the laser power above $250 \mathrm{~W}$ and/or decreasing the laser scanning speed below $100 \mathrm{~mm} / \mathrm{min}$ it's expected that localized liquid phase sintering occurs. The microstructure analysis in section 4.5.1 supports this finding.

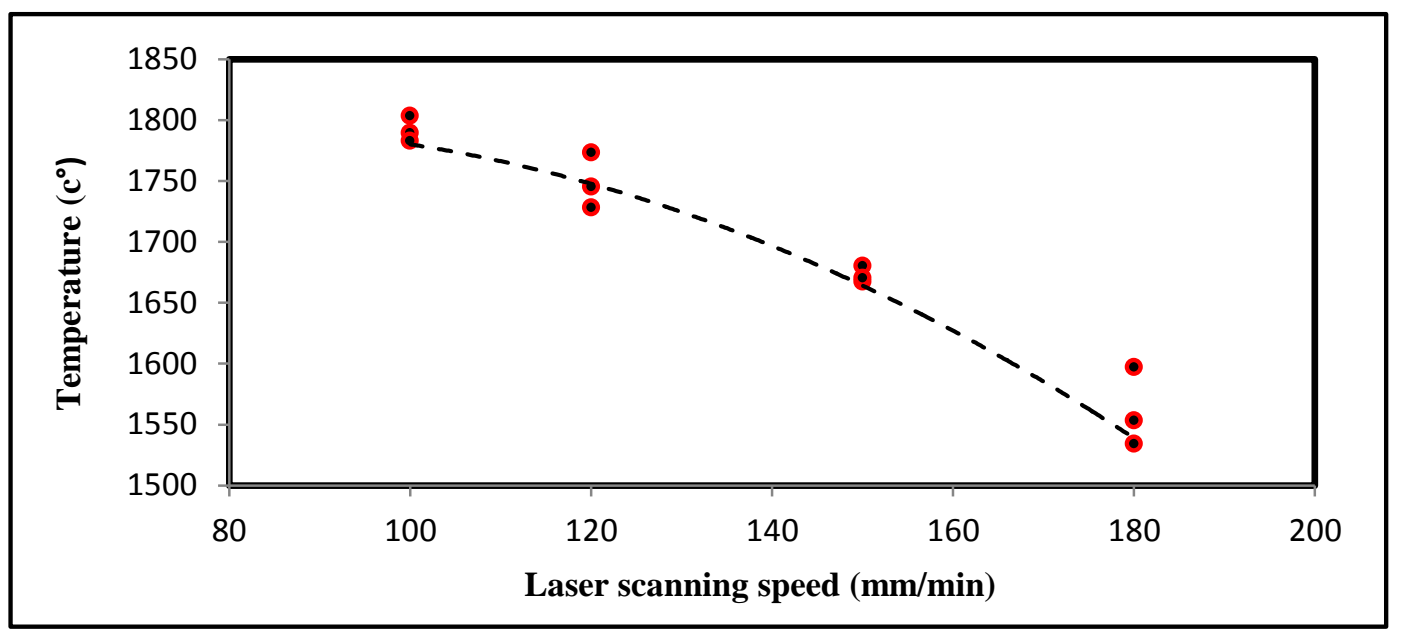

Figure 2: Temperature vs. laser scanning speed at laser power $230 \mathrm{~W}$.

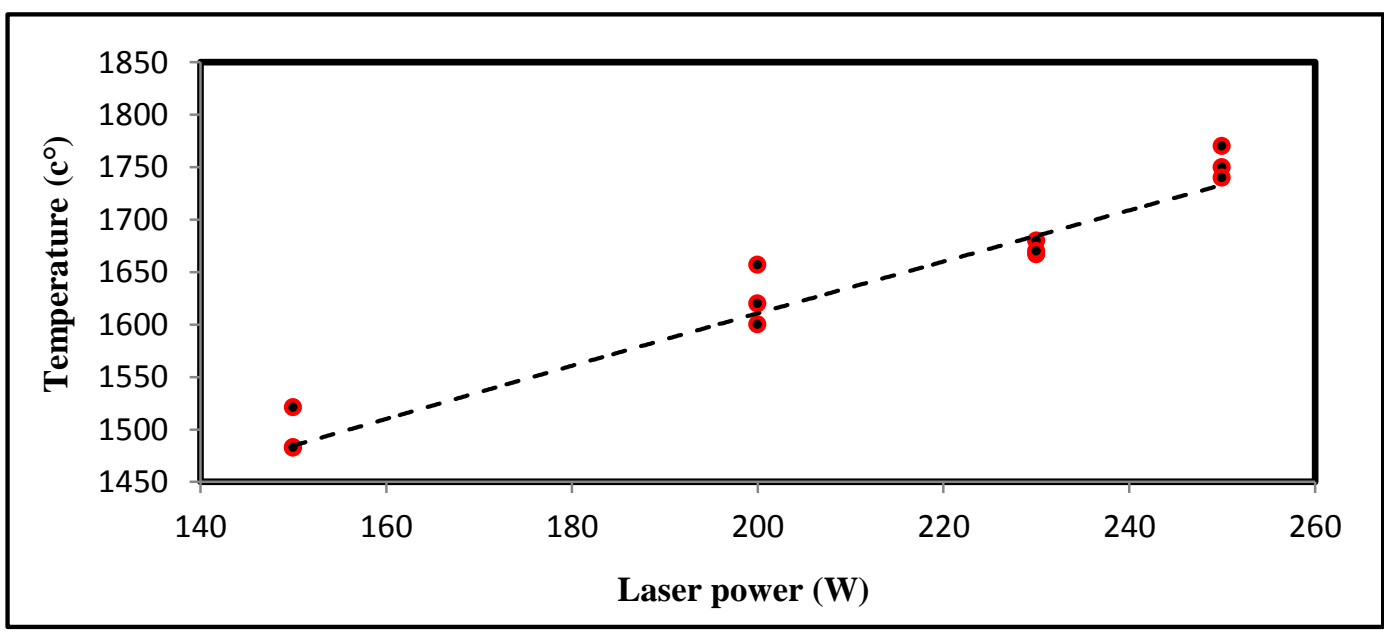

Figure 3: Temperature vs. laser power at laser scanning speed $150 \mathrm{~mm} / \mathrm{min}$. 


\subsection{Effect of laser power and laser scanning speed on physical properties of sintered layer}

Density and porosity are very important physical properties of the sintered ceramic parts. The influence of the laser sintering parameters on the density and porosity has been investigated. Figure 4 and

Figure 5 show the density and apparent porosity, respectively, of the laser sintered samples as a function of laser scanning speed at laser power $230 \mathrm{~W}$. It is observed that at laser power of $230 \mathrm{~W}$, increasing laser scanning speed from 40 to $150 \mathrm{~mm} / \mathrm{min}$ leads to an increase in average density from $2.93 \mathrm{gm} / \mathrm{cm} 3$ to $3.54 \mathrm{gm} / \mathrm{cm} 3$, and to decrease in apparent porosity of the sintered layer from $11.1 \%$ to $4.34 \%$. But after scanning speed $150 \mathrm{~mm} / \mathrm{min}$ until 180 $\mathrm{mm} / \mathrm{min}$, the density of the sintered part decreases to be $3.219 \mathrm{gm} / \mathrm{cm} 3$ and the apparent porosity increases to be $7.83 \%$. Since at very low scanning speed (left hand side of 150 $\mathrm{mm} / \mathrm{min}$ ), instability of the molten powder and trapped bubbles results from key hole formation were performed due to an increase in the duration of the interaction time between the laser beam and surface which cause further increasing in delivered energy and temperature that cause over sintering $[3,11]$. Over sintering due to high temperature (high laser power) or long sintering time (low laser scanning speed) deteriorates the final product quality. The dimensions of over sintered parts do not meet the manufacturing requirements and a few bubbles exit in the interior of the parts which decrease the density as shown in Figure 6. And at very high speed (right hand side of $150 \mathrm{~mm} / \mathrm{min}$ ), the duration of the interaction between the laser beam and surface decreased and insufficient energy delivered to ceramic powder which consequently cause not complete sintering and decrease the density [4].

Figure 7 and Figure 8 show the density and apparent porosity, respectively, of the laser sintered samples as a function of laser power at laser scanning $150 \mathrm{~mm} / \mathrm{min}$. It is observed that at laser scanning speed of $150 \mathrm{~mm} / \mathrm{min}$, increasing laser power from 200 to $230 \mathrm{~W}$ leads to an increase in average density from $3.37 \mathrm{gm} / \mathrm{cm}^{3}$ to $3.54 \mathrm{gm} / \mathrm{cm} 3$, and to decrease in apparent porosity of the sintered layer from $5.81 \%$ to $4.34 \%$. Increase the laser power to 300 $\mathrm{W}$, leads to decrease the density of the sintered part to $3.31 \mathrm{gm} / \mathrm{cm}^{3}$ and increases the apparent porosity to be $8 \%$. Since more energy is delivered into the powder by increasing laser power that lead to enhancement the bonding mechanism between particles which consequently increase the density and decrease the porosity of the sintered sample. Further increasing laser power leads to over sintering as explained previously, see Figure 6.

Finally, it can be concluded the maximum density of $3.54 \mathrm{gm} / \mathrm{cm}^{3}$ and minimum apparent porosity of $4.34 \%$ are obtained at laser power $230 \mathrm{~W}$ and laser scanning speed $150 \mathrm{~mm} / \mathrm{min}$. These values represent approximately $90 \%$ from the theoretical density of the alumina 3.96 $\mathrm{gm} / \mathrm{cm}^{3}$.

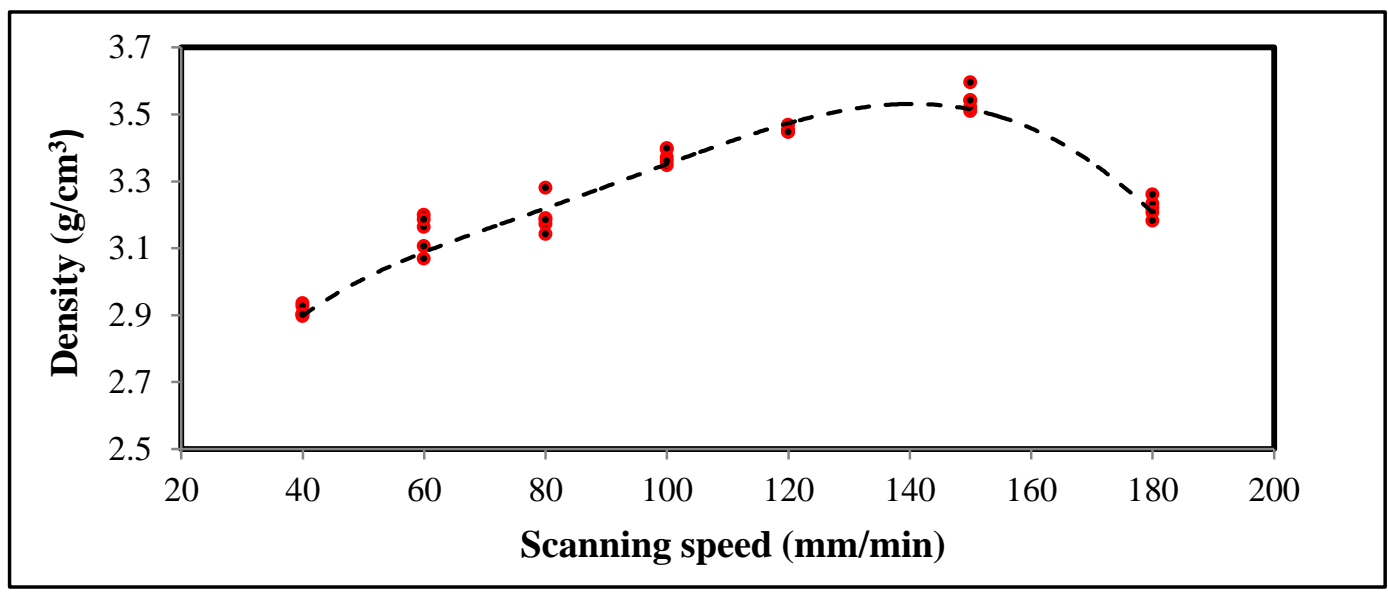




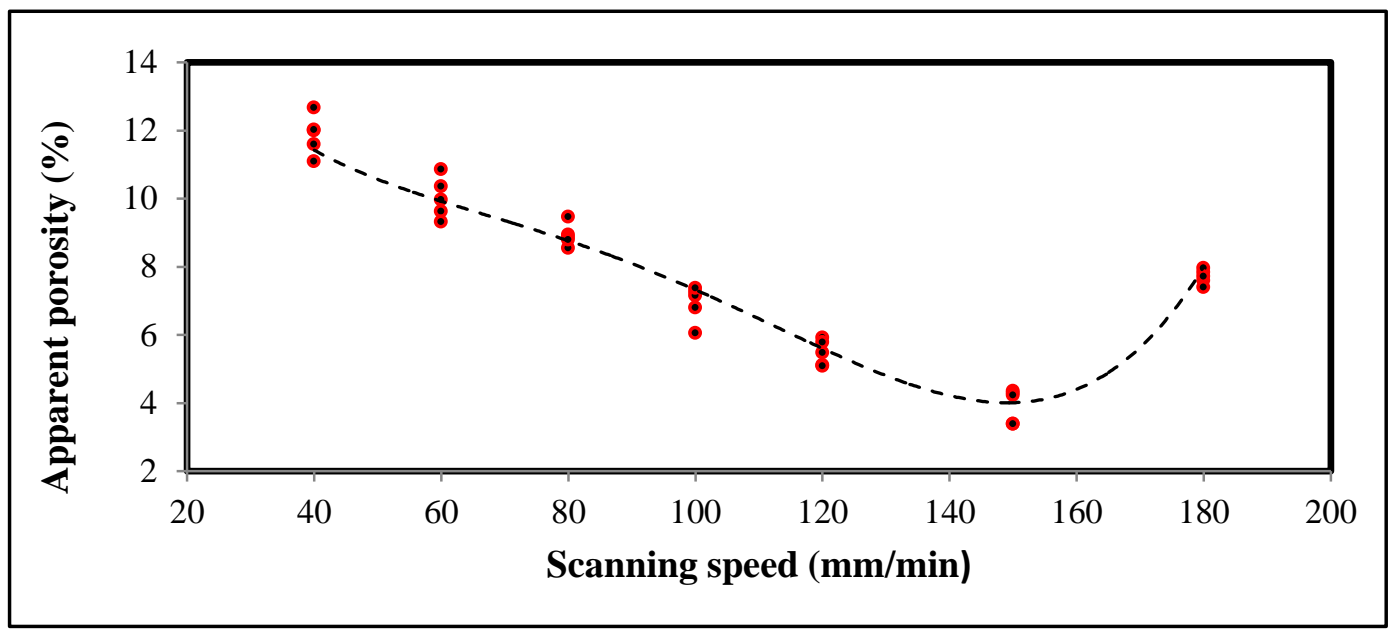

Figure 4: Average density vs. scanning speed at laser power $230 \mathrm{~W}$.

Figure 5: Apparent porosity percentage vs. scanning speed at laser power $230 \mathrm{~W}$

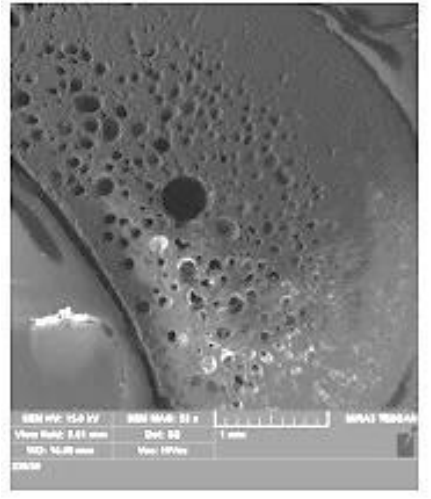

(a)

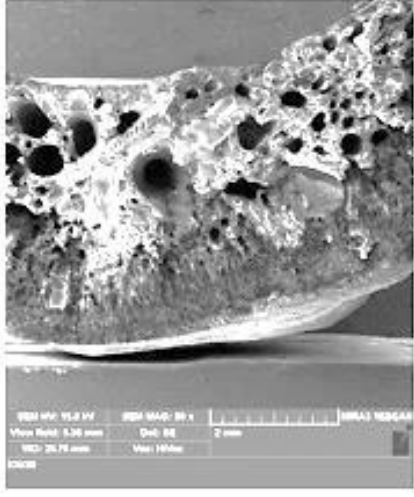

(b)

Figure 6: $\mathrm{SEM}$ micrograph of laser sintered layer made using at $\mathbf{P}=\mathbf{2 3 0} \mathrm{W}$ and $V=40 \mathrm{~mm} / \mathrm{min}$ : (a) polished cross section (b) fracture surface.

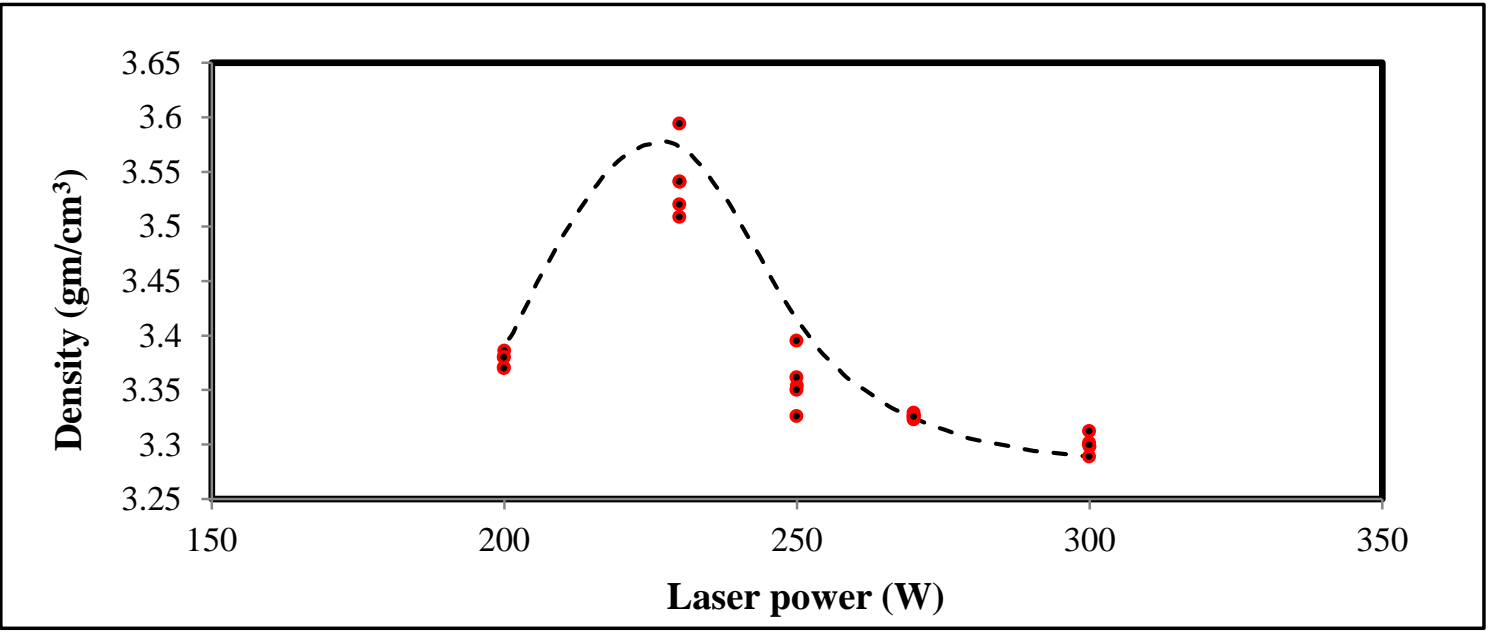

Figure 7: Average density vs. laser power at laser scanning speed $150 \mathrm{~mm} / \mathrm{min}$. 


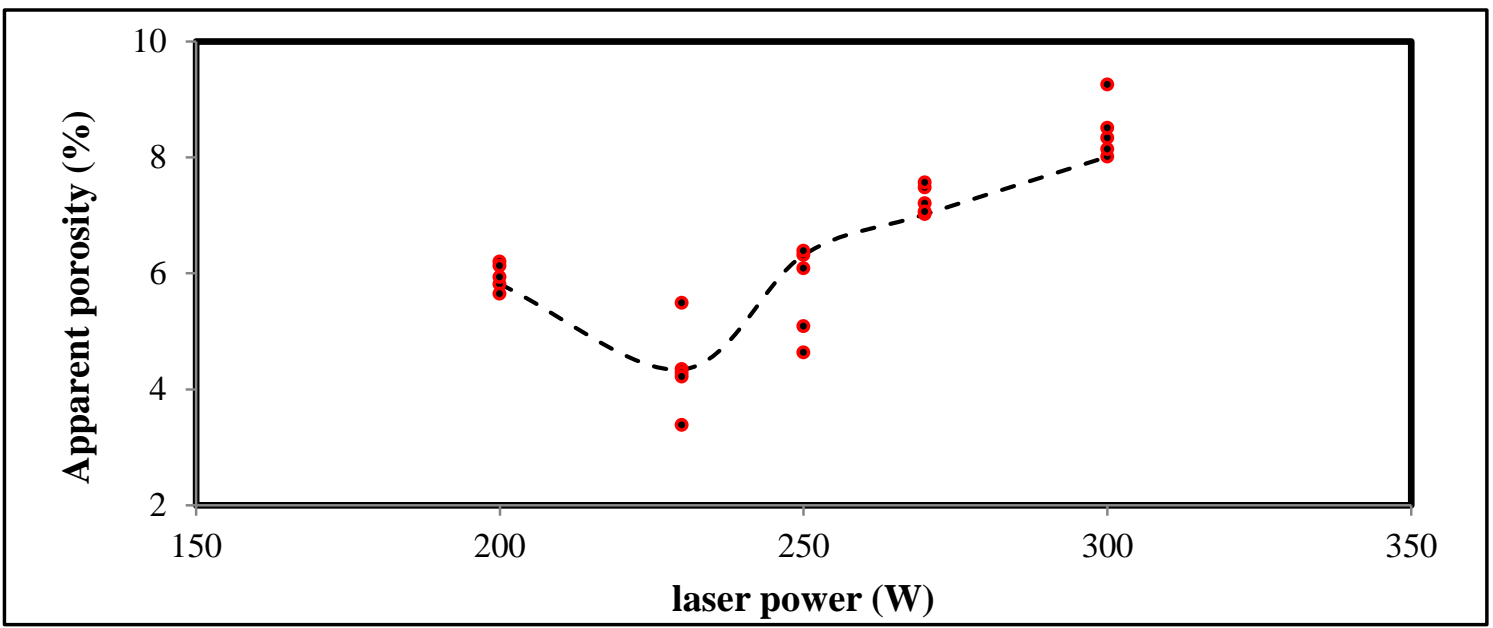

Figure 8: Apparent porosity percentage vs. laser power at laser scanning speed $150 \mathrm{~mm} / \mathrm{min}$.

\subsection{Effect of laser power and laser scanning speed on surface roughness (Ra) of sintered layer}

Figure 9 represents the relationship between the surface roughness $(\mathrm{Ra})$ of the laser sintered layer and the scanning speed as well as laser powers. It was found that, increasing the laser power and/or decreasing scanning speed leads to increase the surface roughness. Since, increasing laser power and/or decreasing laser scanning speed leads to increasing the amount of energy that delivered to the ceramic powder that results in tending the sintered particles to form larger spherical structures due to their effort to reduce the free enthalpy by optimizing the ratio between the area of free surfaces and the related volume which cause coarsening that increase surface roughness [12]. And increase the scanning speed lead to decrease the interacting time between laser and sintered surface, which lead to improve the surface quality by minimizing the possibility of plasma formation [11].

\subsection{Microstructure evaluation}

Because of the close relation between the properties and the microstructure, more work have been focused on the processing of ceramics in order to modify the microstructure and enhance the material properties so as to control the proportion and morphology of ceramic materials.

\subsubsection{Effect of the laser power and scanning speed on the grain size}

Figure 10 shows SEM micrographs of laser sintered sample by using laser power of $230 \mathrm{~W}$ and different scanning speeds 60,100 and $150 \mathrm{~mm} / \mathrm{min}$. It is observed that the decrease in the laser scanning speed at power $230 \mathrm{~W}$ leads to increase in the grain size (grain growth). Because of decreasing laser scanning speed results in increase in the duration of the interaction between the laser beam and surface which cause more energy is delivered to the powder. Hence particles tend to form larger spherical structures due to their effort to reduce the free enthalpy by optimizing the ratio between the area of free surfaces and the related volume which finally lead to coarsening which consequently affect the physical and mechanical properties of the sintered part [12]. Based on the results obtained from the physical properties (density and porosity) at section 3.5, the best physical properties can be obtained by applying laser power $230 \mathrm{~W}$ and laser scanning speed $150 \mathrm{~mm} / \mathrm{min}$. This is 
cleared in microstructure evaluation as shown in Figure 10(c) where minimum grain size and low porosity.

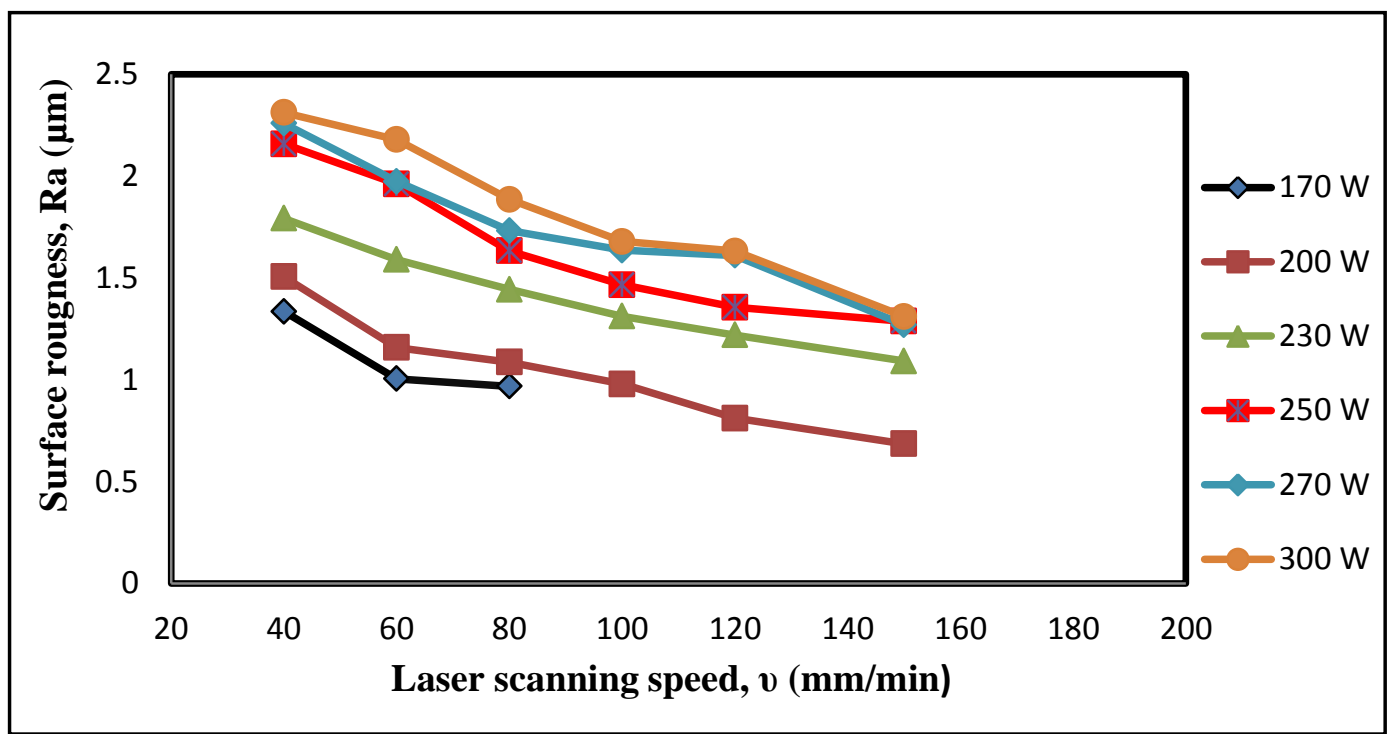

Figure 9: Surface roughness of the monolayer sintered vs. laser scanning speed $v$. and laser power.

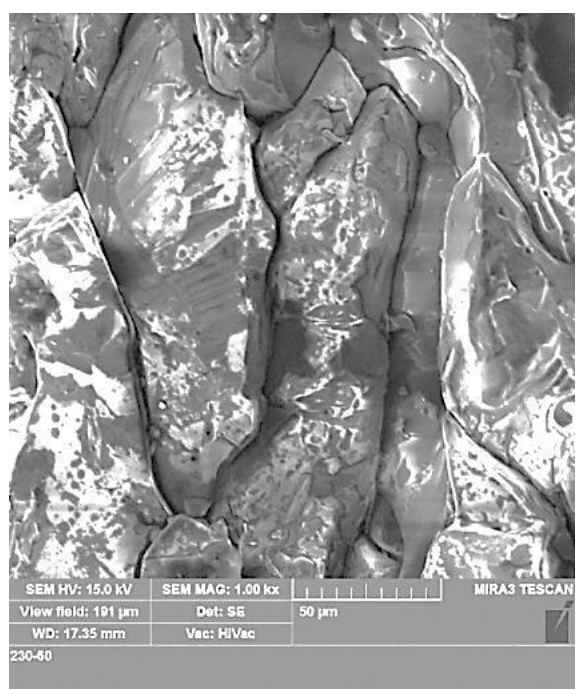

(a)

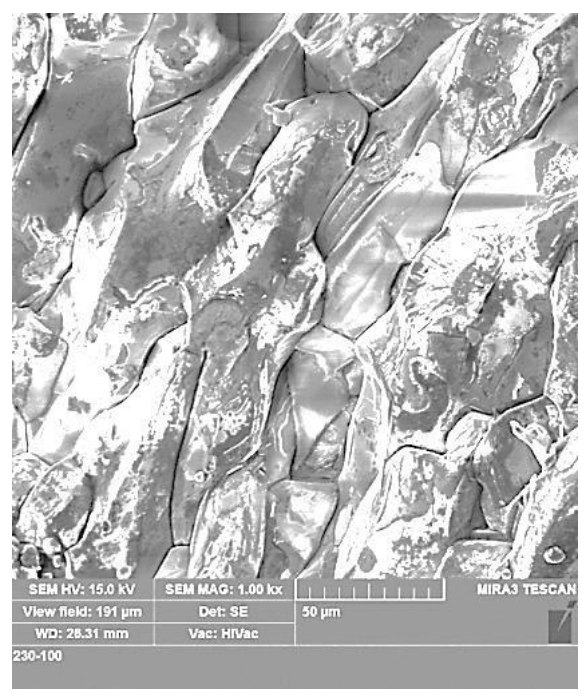

(b) 


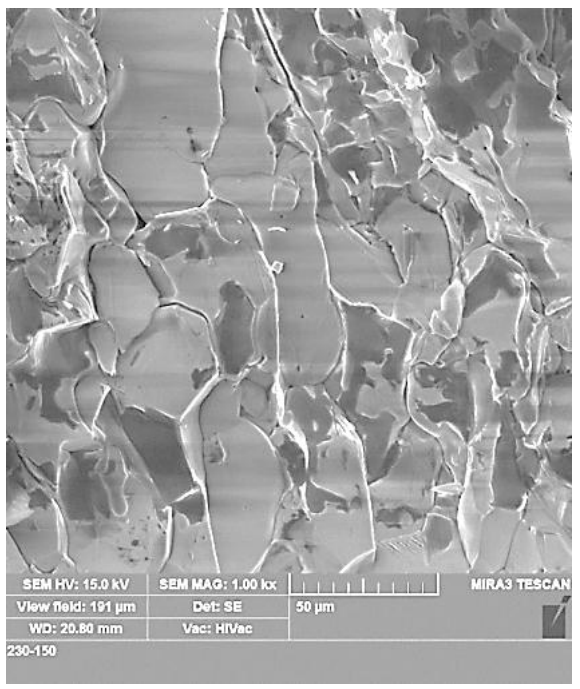

(c)

Figure 10: SEM micrographs of a cross section of laser sintered alumina made using $230 \mathrm{~W}$ power and different speeds (a) $60 \mathrm{~mm} / \mathrm{min}$ (b) $100 \mathrm{~mm} / \mathrm{min}$ (c) $150 \mathrm{~mm} / \mathrm{min}$

Figure 11 shows SEM micrographs of laser sintered sample by using different laser powers 200, 230, 250 and $300 \mathrm{~W}$ at laser scanning speed of $150 \mathrm{~mm} / \mathrm{min}$. It is observed that the increase in the laser power at laser scanning speed $150 \mathrm{~mm} / \mathrm{min}$ leads to increase in the grain size (grain growth). Since increasing laser power/energy results in particles tend also to form larger spherical structures due to their effort to reduce the free enthalpy by optimizing the ratio between the area of free surfaces and the related volume which finally lead to coarsening the microstructure and consequently affect the physical and mechanical properties of the sintered part [12].

Finally, it can be concluded that from Figure 10 and

Figure 11 the optimum microstructure can be obtained by applying laser power $230 \mathrm{~W}$ and laser scanning speed $150 \mathrm{~mm} / \mathrm{min}$ that indicate the results of the physical properties testing at section 3.1.

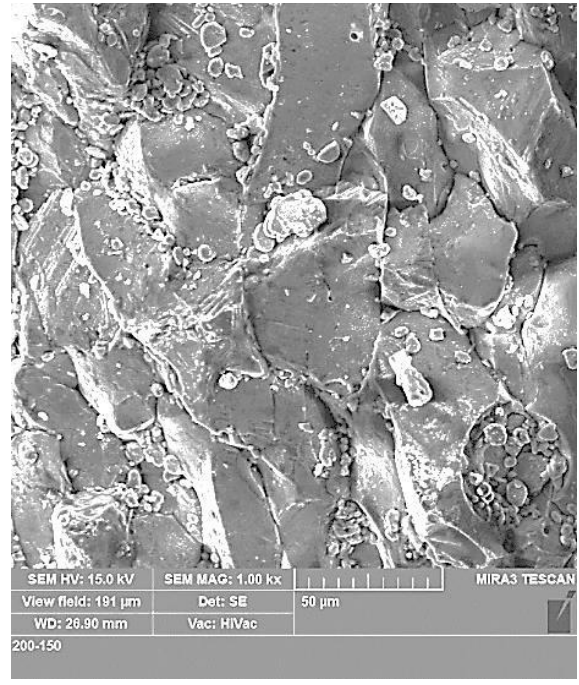

(a)

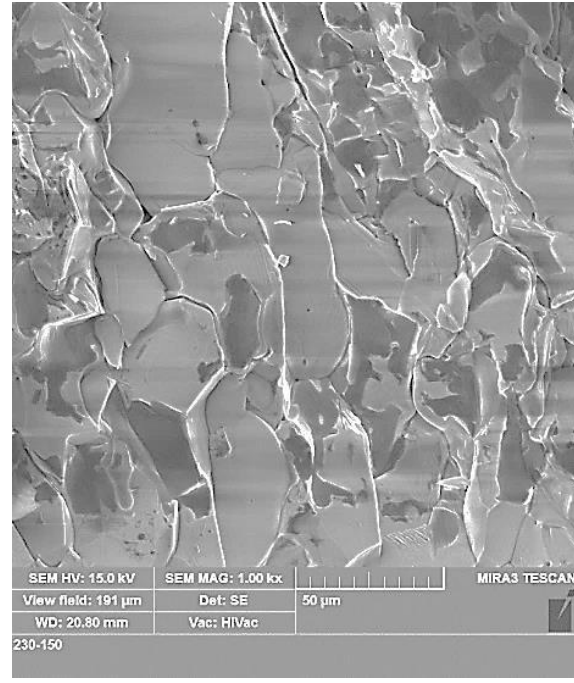

(b) 


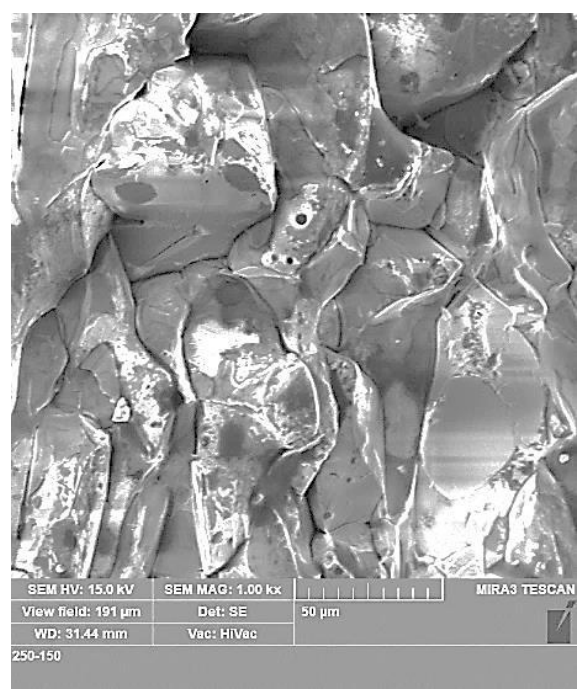

(c)

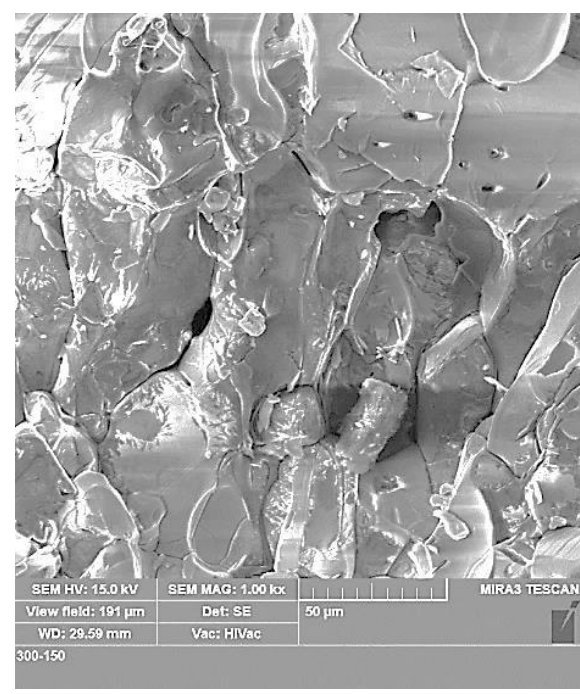

(d)

Figure 11: SEM micrographs of a cross section of laser sintered alumina at scanning speed $150 \mathrm{~mm} / \mathrm{min}$ and different powers: (a) $200 \mathrm{~W}$ (b) $230 \mathrm{~W}$ (c) $250 \mathrm{~W}$ (d) $300 \mathrm{~W}$.

\section{Conclusion}

Ceramic laser sintering has been successfully conducted with a $330 \mathrm{~W}$ pulsed Nd: YAG laser. The present investigation has clearly demonstrated the significant effect of laser sintering process parameters (laser power and laser scanning speed) on the quality (monolayer surface roughness, physical (density and porosity) and microstructure of ceramic laser-sintered components.

The results show that, increasing of the laser power and/or decreasing of the laser scanning speed leads to increase the monolayer surface roughness, increasing the grain size (grain growth) and increasing of the density of the sintered part until certain value for laser power and/or laser scanning speed the density decreased due to over sintering. The maximum density of $3.54 \mathrm{gm} / \mathrm{cm}^{3}$ and minimum porosity of $4.34 \%$ can be obtained by applying laser power $230 \mathrm{~W}$ and laser scanning speed $150 \mathrm{~mm} / \mathrm{min}$.

\section{References}

[1] A. Standard, "F2792. 2012. Standard Terminology for Additive Manufacturing Technologies," ASTM F2792-10e1, 2012.

[2] F. Calignano, D. Manfredi, E. Ambrosio, L. Iuliano, and P. Fino, "Influence of process parameters on surface roughness of aluminum parts produced by DMLS," The International Journal of Advanced Manufacturing Technology, vol. 67, pp. 2743-2751, 2013.

[3] W. Wang, S. Ma, J. Fuh, L. Lu, and Y. Liu, "Processing and characterization of lasersintered $\mathrm{A} 12 \mathrm{O} 3 / \mathrm{ZrO} 2 / \mathrm{SiO} 2, "$ The International Journal of Advanced Manufacturing Technology, vol. 68, pp. 2565-2569, 2013.

[4] C. Ader, "Direct Laser Sintering of Ceramics," State of the Art Report, Fraunhofer Institute of Production Technology IPT, Aachen, Germany.

[5] I. Shishkovsky, I. Yadroitsev, P. Bertrand, and I. Smurov, "Alumina-zirconium ceramics synthesis by selective laser sintering/melting," Applied Surface Science, vol. 254, pp. 966-970, 2007.

[6] H.-C. Yen, M.-L. Chiu, and H.-H. Tang, "Laser scanning parameters on fabrication of ceramic parts by liquid phase sintering," Journal of the European Ceramic Society, vol. 29, pp. 1331-1336, 2009. 
[7] U. Lakshminarayan, "Selective laser sintering of ceramic materials," Dissertation Abstracts International(USA), vol. 53, p. 215, 1992.

[8] B. Qian, "Laser sintered materials with Non-equilibrium structures," 2014.

[9] E. Fayed, A. Elmesalamy, M. Sobih, and Y. Elshaer, "Multi-Objective Optimization for Alumina Laser Sintering Process," Lasers in Manufacturing and Materials Processing, vol. 3, pp. 174-190, 2016.

[10] A. S. E. Elmesalamy, "Narrow Gap Laser Welding of 316L Stainless Steel for Potential Application in the Manufacture of Thick Section Nuclear Components," Ph.D., The University of Manchester, Faculty of Engineering and Physical Sciences, 2013

[11] A. Elmesalamy, L. Li, J. Francis, and H. Sezer, "Understanding the process parameter interactions in multiple-pass ultra-narrow-gap laser welding of thick-section stainless steels," The International Journal of Advanced Manufacturing Technology, vol. 68, pp. $1-17,2013$.

[12] F. Klocke and C. Ader, "Direct laser sintering of ceramics," in Solid Freeform Fabrication Symposium, Austin, Texas, 2003, pp. 447-455. 